\title{
Reducing uncertainty in small-catchment flood peak estimation
}

\author{
Gianni Vesuviano ${ }^{1, a}$, Lisa Stewart ${ }^{1}$, Tracey Haxton ${ }^{2}$, Andy Young ${ }^{2}$, Tim Hunt ${ }^{3}$, Peter Spencer ${ }^{3}$ and Mark Whitling ${ }^{3}$ \\ ${ }^{1}$ Centre for Ecology \& Hydrology, Maclean Building, Benson Lane, Crowmarsh Gifford, Wallingford, OX10 8BB, UK \\ ${ }^{2}$ Wallingford HydroSolutions, Maclean Building, Benson Lane, Crowmarsh Gifford, Wallingford, OX10 8BB, UK \\ ${ }^{3}$ Environment Agency, Horizon House, Deanery Road, Bristol, BS1 9AH, UK
}

\begin{abstract}
Every year in the UK, many flood risk assessments are carried out on small catchments, typically draining areas of less than $25 \mathrm{~km}^{2}$. Standard hydrological practice in all UK catchments is to apply the methods presented in the Flood Estimation Handbook (FEH) and its subsequent updates. FEH methods are practical, relatively easy to apply and based on extensive statistical analyses. However, uncertainties can be large, especially in atypical catchments, and small catchments can present unique challenges in terms of heavy urbanisation and rapid flood responses. Compared to larger catchments, small catchment flood data are limited. In this study, we use a dataset of annual maxima and digital catchment descriptors at 205 small catchments to benchmark the QMED and Q100 estimation performance of current UK flood estimation methods: the FEH statistical method, ReFH2 and MacDonald and Fraser's method, in rural and urbanised catchments separately. All methods perform similarly in rural catchments overall, although MacDonald and Fraser's method underestimates QMED in urbanised catchments. The methods show a larger factorial standard error against this small catchment dataset than they do against typical datasets of mixed-size catchments. Further work will evaluate the performance of ReFH2 in combination with the latest FEH13 rainfall model.
\end{abstract}

\section{Introduction}

Catchments draining a small area (typically less than $25 \mathrm{~km}^{2}$ ) make up a large proportion of the UK river network. Small catchments present particular challenges because they tend to be more homogeneous than larger catchments, so have the potential to be heavily urbanised or permeable across the whole area. The smaller dimensions of such catchments, together with the fact that they have proportionally fewer attenuation features in their flow paths, also result in faster and peakier runoff responses, which can be exacerbated by heavy urbanisation.

In the UK, flood design practice is based on the methods described in the Flood Estimation Handbook (FEH) [1] and subsequent updates. Current UK guidance for small catchments [2] recommends the use of existing FEH methods except in particular cases (e.g. highly permeable or heavily urbanised catchments). However, older methods are still used in some cases, principally because they are easy to apply and do not require digital catchment descriptors and specialist software. The FEH methods have been designed to apply to a wide range of catchment sizes from 0.5 to several thousand $\mathrm{km}^{2}$ in area. However, the bulk of the catchments used to calibrate the methods are hundreds of square kilometres in area, with only a few draining an area less than $25 \mathrm{~km}^{2}$.

The aim of this research (funded by the Joint Defra/Environment Agency Flood and Coastal Erosion

\footnotetext{
a Corresponding author: giaves@ceh.ac.uk
}

Risk Management R\&D Programme) is to evaluate the performance of current FEH methods in small catchments, identify any catchment characteristics that are more likely to lead to larger errors and to propose countermeasures in these cases. The method of estimating QMED, the median annual maximum flood, in small catchments developed by MacDonald and Fraser [3] is also considered.

\section{Data}

A set of 205 gauged catchments up to $40.9 \mathrm{~km}^{2}$ in area was identified, with a mean gauged record length of 27.4 years. These were selected from an initial set of 600 catchments, from which flow data were subject to an extensive review of quality. The median annual maximum value of peak flow (QMED) is available for all 205 catchments, allowing modelled QMED estimates to be validated. Full annual maximum (AMAX) flow series, allowing estimates of rarer flood peaks to be validated, are available for 180 catchments. Figure 1 maps the catchments, showing the length of the available AMAX record (or number of years contributing to the QMED value where no AMAX record is available). Of the 205 gauged catchments, 27 are under $5 \mathrm{~km}^{2}, 128$ are between 5 and $25 \mathrm{~km}^{2}$, and 60 are between 25 and $40.9 \mathrm{~km}^{2}$. Some catchments above $25 \mathrm{~km}^{2}$ are included in this data set as it is intended to provide calibration data for new smallcatchment methods in future work. These larger 


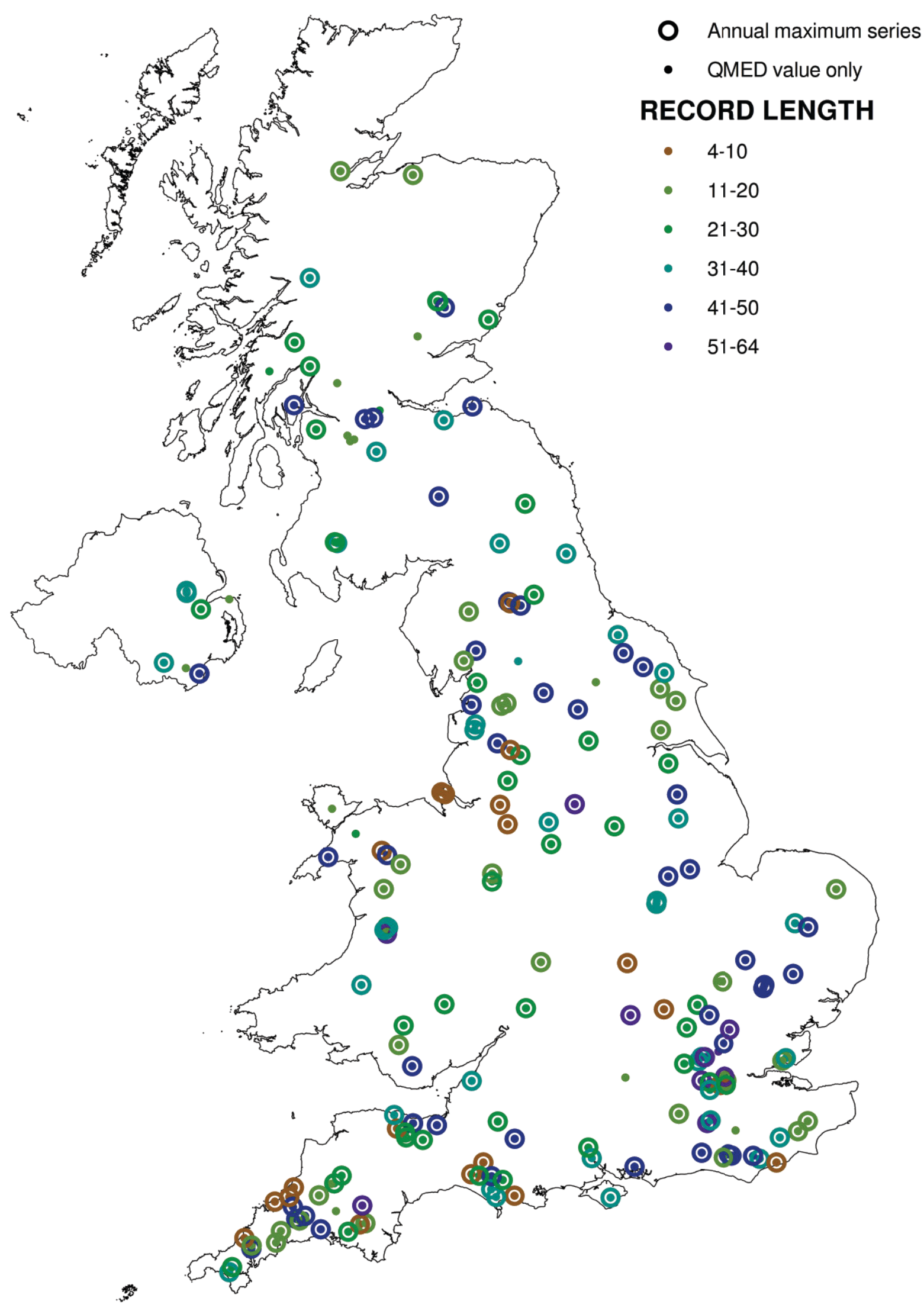

Figure 1. Location of study gauging stations. 
catchments are intended to prevent sudden discontinuities or mismatches between new small-catchment and existing all-catchment methods in the transitional range of areas just above $25 \mathrm{~km}^{2}$.

Key FEH catchment descriptors including SAAR (catchment average annual rainfall for the standard period 1961-90), BFIHOST (baseflow index using the Hydrology of Soil Types classification), URBEXT 2000 (extent of urbanisation in the year 2000) and FARL (index of flood attenuation due to reservoirs and lakes) were obtained for all 205 catchments from the FEH Web Service [4] and the National River Flow Archive [5] in order to provide input data for ungauged estimation of flood peaks. It was found that the representation of different types of catchment within the data set broadly reflected that of catchments of all sizes in the UK.

\section{Modelling methods}

In the UK, the FEH and its subsequent updates present two methods of flood frequency estimation, which have become standard practice. The first is the improved FEH statistical method [6], which is a flexible technique that makes use of AMAX and catchment descriptor data from across the UK, and the second is the recently updated $\mathrm{ReFH} 2$ design method [7], based on the Revitalised Flood Hydrograph (ReFH) model [8]. The analysis described here has also considered the performance of MacDonald and Fraser's QMED equation for small catchments [3]. Each approach is discussed in more detail below.

\subsection{Improved FEH statistical method}

The improved FEH statistical method is based on the index-flood method [9]. Its two key elements are the estimation of QMED, the index flood at the site of interest, and the definition of a flood growth curve giving the ratio between QMED and the flood of the required return period using L-moment estimation [10]. Although the currently recommended method follows the same structure as that published in FEH Volume 3 [11], almost every aspect of the procedure has since been modified.

The improved FEH statistical method has been calibrated against a very large data set of approximately 19,700 annual maximum flood peaks at 602 catchments with a wide range of physical properties. At ungauged sites the index flood, QMED, is estimated by a regression equation on catchment descriptors:

$$
\begin{aligned}
& Q M E D=8.3062 A R E A^{0.8510} 0.1536^{1000 \text { SAAR }} \ldots \\
& F A R L^{3.4451} 0.0460^{\text {BFIHOST }}{ }^{2}
\end{aligned}
$$

where all variables on the right side of the equation are the catchment descriptors defined by Bayliss [12]. It is recommended that a donor transfer procedure using the QMED value at one or more nearby gauged sites should be applied to correct the QMED value estimated from Equation 1 [13].

If the catchment is urbanised, the estimated value of QMED is multiplied by an urban adjustment factor, which revises the estimate upward in proportion to the level of urbanisation in the catchment [14].

Flood peaks rarer than QMED are estimated via a dimensionless flood growth curve, which relates the Tyear flood peak to a multiple of QMED. It is derived by identifying a pooling-group, a set of gauged catchments that is similar to the ungauged catchment in terms of key catchment descriptors, with a combined total record length of at least 500 years. The annual maximum series for each gauged catchment is standardised by the median, and catchment L-moments are calculated. The Lmoments are pooled, with catchments that are more similar to the ungauged catchment receiving a heavier weighting. The pooled L-moments are used to parameterise a Generalised Logistic (GLO) distribution, which is intended to represent the general flood growth behaviour of catchments similar to the ungauged catchment. Where gauged AMAX values are available at the site of interest, the enhanced single-site methodology is used and the at-site L-moments are given greater weight in the pooling procedure.

In this study, the improved FEH statistical method is tested with and without donor transfer, recognising that donor transfer is frequently not applied in small catchments.

\subsection{The Revitalised Flood Hydrograph (ReFH) method}

The original ReFH design method [15] constructs a flood hydrograph of a specified return period from a set of probabilistic inputs and is based on the Revitalised Flood Hydrograph model [8]. Recent research has updated the method considerably; the current version is now known as ReFH2 [7].

The conceptual model at the heart of ReFH2 combines a loss component, urban and rural direct runoff components, both based on a unit hydrograph, and a baseflow component. The design method requires the estimation of four model parameters and two initial conditions. New parameters in ReFH2 control the fraction of net rainfall to be routed via the new urban unit hydrograph (default $1.567 \times \mathrm{URBEXT}_{2000}$ ), the ratio of the urban unit hydrograph's time-to-peak relative to that of the original rural unit hydrograph (default 0.5 ), the fraction of the urban area that is impermeable (default 0.3 ) and the constant runoff coefficient of the impermeable area (default 0.7 ).

In the absence of at-site calibration data, all catchment-dependent parameter values are determined via regression equations based on catchment descriptors. These equations were re-calibrated for ReFH2. Consequently, ReFH2 is applicable to both permeable and heavily urbanised catchments, and is suitable for return periods up to 1000 years. ReFH2 is not applicable to catchments over $1000 \mathrm{~km}^{2}$ or to catchments affected by attenuation due to lakes and reservoirs (FARL $<0.9$ ) unless a separate reservoir routing procedure is included.

The ReFH2 design method can be used with design storm inputs from either the six-parameter rainfall depthduration-frequency (FEH99) model presented in 
Volume 2 of the FEH [16] or with the newly released FEH13 rainfall model [17]. Although the analysis described here has used the FEH99 model, ongoing research is considering the effect of the FEH13 rainfall inputs on the peak flow estimates.

\subsection{MacDonald and Fraser's equation}

MacDonald and Fraser's improved equation for the median annual flood in small catchments [3] was intended to further reduce the error in $Q M E D$ over the improved FEH statistical method for catchments between 0.5 and $25 \mathrm{~km}^{2}$ in area. It is a catchment descriptor-based regression equation, given by:

$$
Q M E D=6.120 A R E A^{0.758} 0.288^{\frac{1000}{S A A R}} 0.042^{B F I H O S T^{2}}
$$

where all terms are defined previously. Development of this equation used a set of 104 essentially rural $\left(\mathrm{URBEXT}_{2000}<0.03\right)$ and 31 more urbanised small catchments with known descriptors and QMED values based on gauged AMAX records. MacDonald and Fraser do not publish any procedure for generating a growth curve that is consistent with their QMED equation and do not propose a mechanism for donor transfer. Nevertheless, since the method was specifically developed for use in small UK catchments, it has been included in the comparison of methods described below.

\subsection{Quantifying performance}

The performance of the ungauged estimation methods is quantified through two statistics. Equation 3 measures ln-error: the mean difference between the natural logarithm-transformed peak flow and its estimate. Equation 4 measures factorial standard error $\left(f_{s e}\right)$ : the spread of difference between the natural logarithmtransformed peak flow and its estimate.

$$
\begin{gathered}
\sum_{i=1}^{n}\left[\ln \left(Q_{\mathrm{mod}, i}\right)-\ln \left(Q_{o b s, i}\right)\right] / n \\
\exp \left\{\sum_{i=1}^{n}\left[\ln \left(Q_{\mathrm{mod}, i}\right)-\ln \left(Q_{o b s, i}\right)\right]^{2} / n\right\}^{0.5}
\end{gathered}
$$

Here, $Q$ refers to a flow peak and the subscripts $\bmod$ and $o b s$ refer to modelled and "observed" values. Natural logarithm transformations of $Q$ are used because they are considered to be more normally distributed. It is noted that the $95 \%$ confidence interval of a flood peak estimate is $\left[\mathrm{Q} / f s e^{2}, \mathrm{Q} \times f s e^{2}\right]$.

In evaluating QMED, the observed value is taken to be the median of recorded annual maxima. In evaluating rarer flood peaks (QT), an enhanced single-site analysis is used as the benchmark against which the three FEH methods (applied as if at ungauged sites) are evaluated. This pools at-site AMAX data with those at similar sites that are deemed suitable for pooling. It is similar to the FEH statistical method, but takes QMED directly from at-site data and applies a greater weight to the at-site AMAX series when calculating of the pooled Lmoments. The requirement to pool data from several catchments means that the enhanced single-site method is applicable to rural catchments, with $\mathrm{URBEXT}_{2000}<0.03$, only. To emphasise that enhanced single-site values of QT are also estimated, albeit in the best way possible according to current practice, the term "difference" might be preferred to "error", although the latter is used here for consistency with the QMED analysis.

\section{Results and discussion}

This section considers the performance of methods for estimating QMED and the 100-year return period flood (Q100) in small catchments, showing results for subsets of permeable, less permeable, wetter and drier catchments separately. The distribution of land and people in the UK means that the majority of catchments overall are rural $\left(\mathrm{URBEXT}_{2000}<0.03\right)$, less permeable $($ BFIHOST $<0.65)$ and wetter $(\mathrm{SAAR} \geq 800)$, while the majority of urbanised catchments are drier $(\mathrm{SAAR}<800)$, but also less permeable. MacDonald and Fraser's method is evaluated for QMED estimation only, as it cannot be used to estimate any other rarity of flood peak. Additionally, as the enhanced single-site method can only be applied in rural catchments, Q100 estimation performance will be considered for rural catchments only.

\subsection{QMED estimation in rural catchments}

Figure 2 plots the error in estimated $\ln (\mathrm{QMED})$ against catchment area for 148 small rural catchments, using point shape and colour to indicate catchments with SAAR above and below $800 \mathrm{~mm}$ and BFIHOST above and below 0.65 . This clearly shows a lack of dependence between catchment area and error in any estimate, therefore that none of the methods is biased when applied to small catchments. Figure 2 suggests that the spread of errors may be higher for catchments that are both permeable and drier, indicated by yellow crosses. However, it is not possible to state this definitively due to the small number (10) of drier permeable catchments.

All tested methods show similar $f_{s e}$ values, however that for $\mathrm{ReFH} 2$ is the smallest. The value of $f_{s e}$ is slightly higher for the FEH statistical method with donor transfer than without, suggesting that donor transfer is not beneficial for small catchments on average. All methods report $f_{s e}$ values that are considerably above that of the improved FEH statistical method applied to its own calibration data set $\left(f_{s e}=1.43\right)$, implying that flood peak estimation in small catchments suffers from wider confidence intervals than in larger catchments.

Figure 2 suggests that the FEH statistical method may underestimate QMED in lower-SAAR, lower-BFIHOST catchments and overestimate QMED in higher-SAAR, higher-BFIHOST catchments, on average. While these catchment groups are too small for the suggestions to be generalised, ReFH2 does not show dependence between error and either the SAAR or BFIHOST value. 

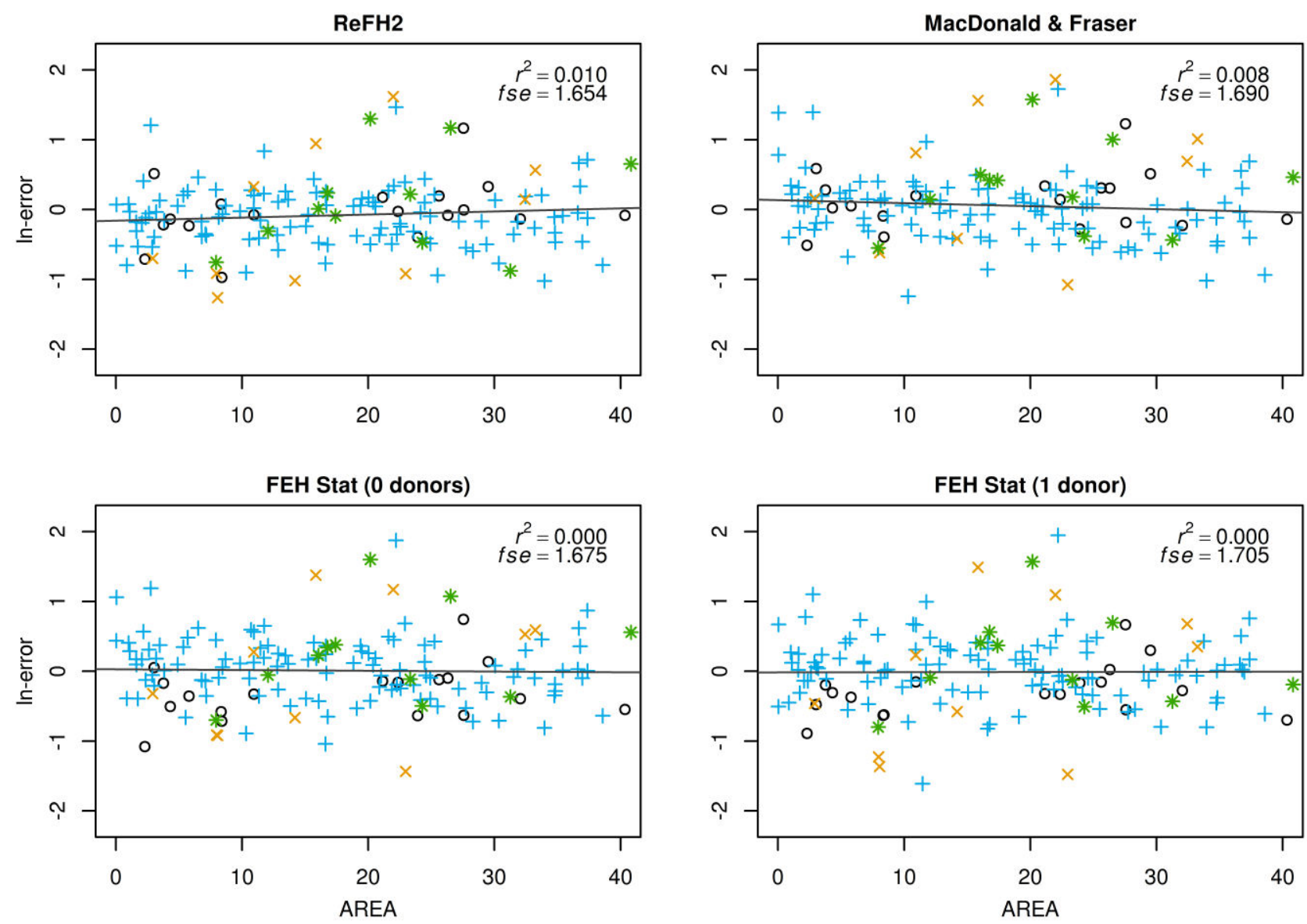

+ SAAR $>800$, BFIHOST $<0.65$

○ SAAR $<800$, BFIHOST $<0.65$

SAAR $>800$, BFIHOST $>0.65$

SAAR $<800$, BFIHOST $>0.65$

Figure 2. Error in estimated $\ln (\mathrm{QMED})$ vs. catchment area for 148 rural small catchments. Solid black lines show least-squares fit.

\subsection{QMED estimation in urban catchments}

Figure 3 plots the error in estimated $\ln (\mathrm{QMED})$ against URBEXT $_{2000}$ for 57 small urban catchments. Here, all methods show a correlation between increasing $\mathrm{URBEXT}_{2000}$ and negative error in the $\ln$ (QMED) estimate, which is significant at the 5-10\% levels for FEH methods and the 20\% level for MacDonald and Fraser's method. The dependency between error and URBEXT 2000 is presumably due to the additional assumptions and modelling steps required to account for urbanisation in FEH methods. MacDonald and Fraser's equation is also the only method that contains no urban adjustment mechanism, as the descriptor URBEXT UR00 $_{20}$ was not found to offer additional explanatory power to the regression. Hence, all effects of urbanisation on QMED are ignored, resulting in a $95 \%$ confidence interval ranging from approximately $0.25^{\times} \mathrm{QMED}$ to $4^{\times} \mathrm{QMED}$. For this reason, the method cannot be recommended under any circumstance for use in non-rural small catchments.

Purely in terms of ln-error and $f s e$, the use of donor transfer improves the FEH statistical method noticeably. Overall, however, there is very little difference between the subplots for the three FEH methods in Figure 3. It is noted that both $f$ se and correlation between ln-error and
$\mathrm{URBEXT}_{2000}$ may be reduced by excluding catchments with $\mathrm{URBEXT}_{2000} \geq 0.6$ from the analysis (dotted green lines on Figure 3).

\subsection{Q100 estimation in rural catchments}

Figure 4 plots the error (or "difference" - see Section 3.4) in estimated $\ln (\mathrm{Q} 100)$ against catchment area for the 131 small rural catchments with at-site AMAX data that allows the use of enhanced single-site analysis. The performance of the methods is largely unchanged at Q100 relative to QMED: there is no dependency between error and catchment area. Furthermore, the spread of errors as measured by $f_{s e}$ is only slightly increased for each method. Hence, the methods are equally as applicable at Q100 as they are at QMED. ReFH2 and the FEH statistical method without donor transfer are equal performers in terms of $f_{s e}$. There is some evidence to suggest that the FEH statistical method may underestimate Q100 in drier and less permeable catchments, indicated by black circles. This underestimation is not mitigated by donor transfer. Although data are too limited for a strong recommendation, it is proposed that $\mathrm{ReFH} 2$ be preferred 

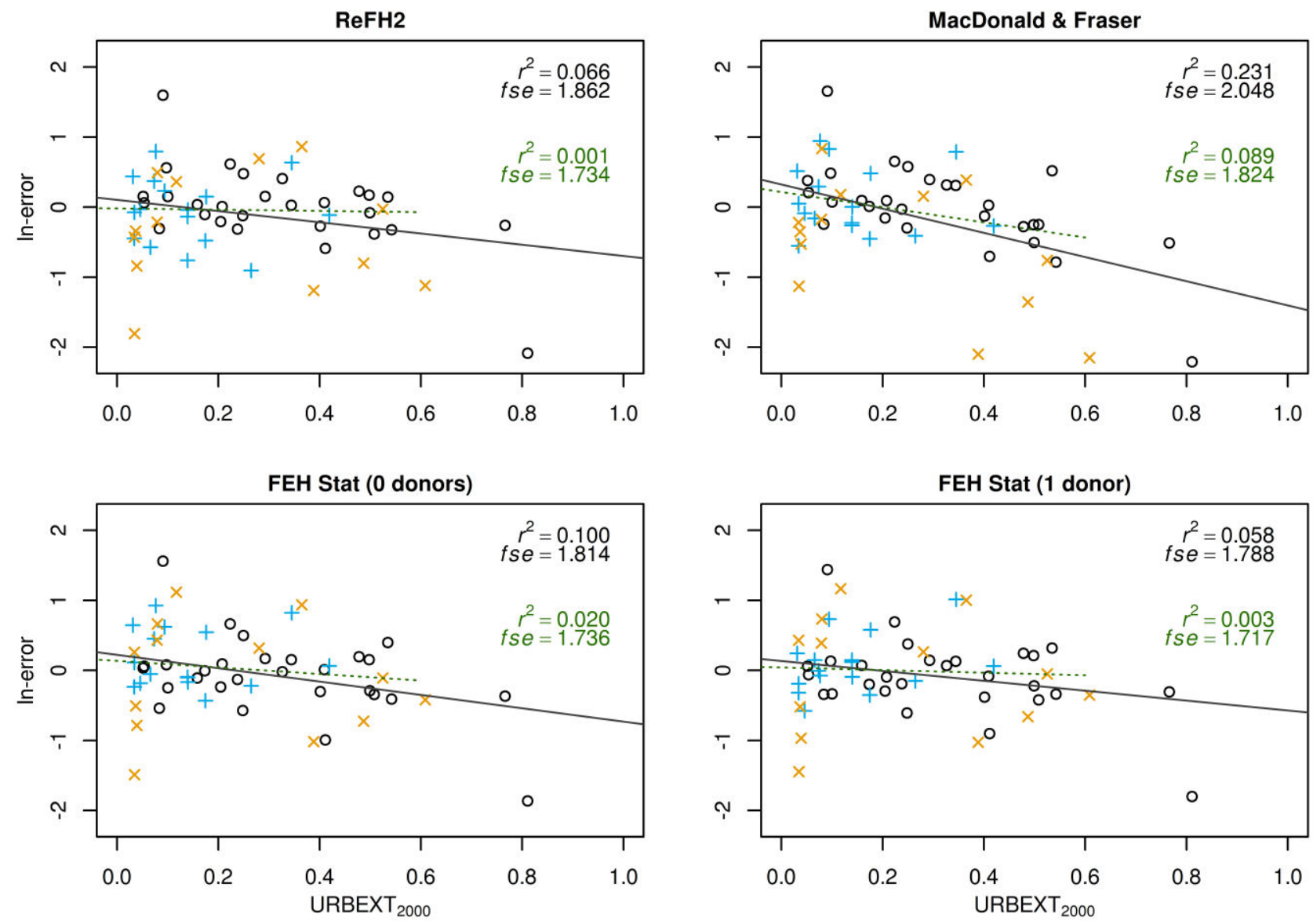

+ SAAR $>800$, BFIHOST $<0.65$

○ $\mathrm{SAAR}<800$, BFIHOST $<0.65$

SAAR $>800$, BFIHOST $>0.65$

SAAR $<800$, BFIHOST $>0.65$

Figure 3. Error in estimated $\ln (\mathrm{QMED})$ vs. $\mathrm{URBEXT}_{2000}$ for 57 urbanised small catchments. Solid black lines show least-squares fit, dotted green lines show least squares fit for 54 catchments with $\mathrm{URBEXT}_{2000}<0.6$.
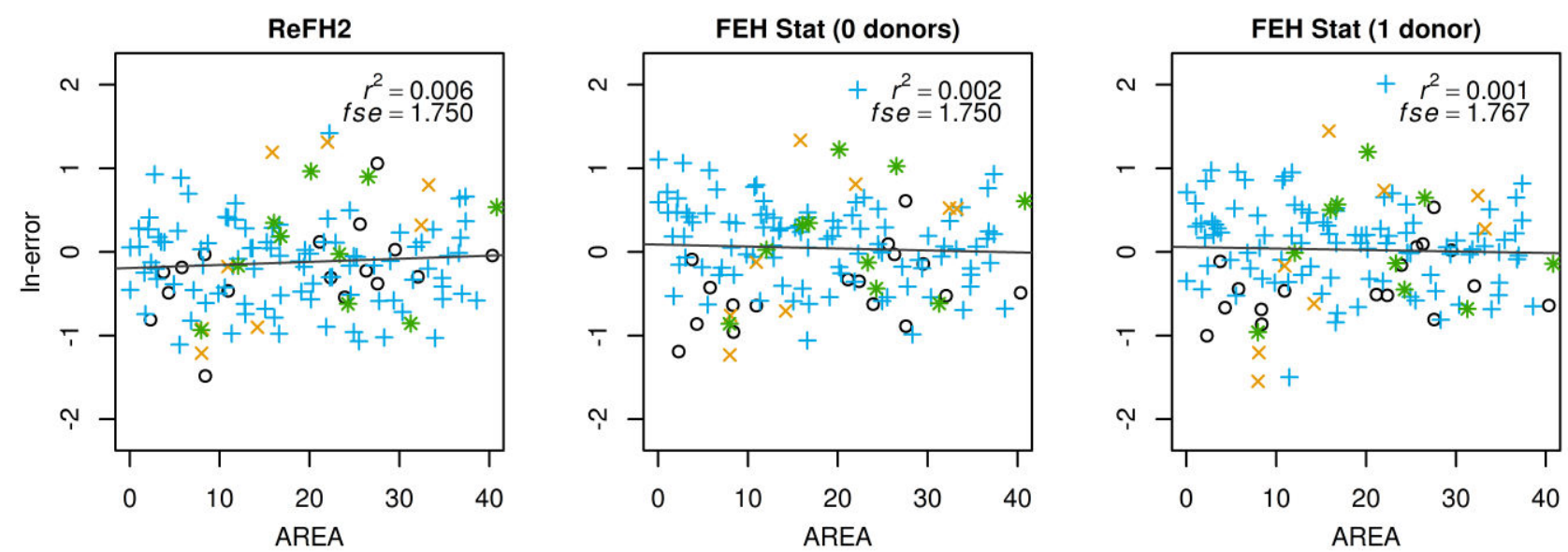

$$
\begin{aligned}
& + \text { SAAR }>800, \text { BFIHOST }<0.65 \quad * \text { SAAR }>800, \text { BFIHOST }>0.65 \\
& \circ \text { SAAR }<800, \text { BFIHOST }<0.65 \quad \times \text { SAAR }<800, \text { BFIHOST }>0.65
\end{aligned}
$$

Figure 4. Error in estimated $\ln (\mathrm{Q} 100)$ vs. catchment area for 131 rural small catchments. Solid black lines show least-squares fit. 
for Q100 estimation in small rural catchments in which both BFIHOST is less than 0.65 and SAAR is less than $800 \mathrm{~mm}$.

FEH statistical flood peak estimates consist of two independent components, an index flood and a growth curve. Donor transfer adjusts the index flood only. Hence, the values of Q100/QMED are the same regardless of whether or not donor transfer is used. The procedure to build the growth curve typically selects 10 to 15 catchments that are hydrologically similar to the ungauged catchment from a pool of around 1000, updated periodically. Catchment area is used as the main criterion for selection. As there are few small catchments in this pool (only 49 are under $40 \mathrm{~km}^{2}$ ), similar pooling-groups, resulting in similar growth curves, tend to be selected for all small catchments. This effect becomes more pronounced as the ungauged catchment becomes smaller and fewer gauged catchments of a similar size are available for pooling. This may result in very unexpected growth curves for small catchments that are somewhat atypical, but not so atypical that a catchment descriptor other than area becomes the dominant criterion for pooling-group selection.

\section{Conclusions}

A data set of 205 gauged small catchments was used to benchmark the performance of current ungauged flood estimation methods, with consideration of catchment urbanisation level, permeability and typical average annual rainfall. Performance at QMED was benchmarked against the median of gauged annual maxima and performance at Q100 was benchmarked via enhanced single-site analysis (for rural catchments only).

From this analysis, it is recommended that ReFH2 be used to estimate QMED in small catchments that are essentially rural (with $\mathrm{URBEXT}_{2000}<0.03$ ) and that either ReFH2 or the FEH statistical method without donor transfer should be used for catchments with higher values of $\mathrm{URBEXT}_{2000}$. Either donor transfer or the exclusive use of ReFH2 should be considered in wetter urbanised catchments (SAAR $>1200)$. Unlike the original ReFH method [2], ReFH2 is equally suitable for use in both permeable and less-permeable catchments and performs well in urbanised catchments. MacDonald and Fraser's method is not recommended for estimating QMED in catchments with any degree of urbanisation, as it is likely to underestimate. It also cannot be recommended in preference to any $\mathrm{FEH}$ method in rural catchments.

All FEH methods are shown, in general, to be equally applicable for estimation of Q100 as they are for estimation of QMED. There is little to choose between any method for Q100 estimation in small rural catchments and no definitive recommendation can be made. However, it is tentatively recommended to prefer ReFH2 if both BFIHOST is less than 0.65 and SAAR is less than $800 \mathrm{~mm}$.

It should be noted that any method is likely to underestimate QMED in extremely urbanised catchments $\left(\mathrm{URBEXT}_{2000} \geq 0.6\right)$. Amendments to the existing methods are required as it is necessary that the methods should be able to model flood peaks for any UK catchment. It should also be noted that all methods may tend to underestimate Q100 in catchments that are dry $(\mathrm{SAAR}<800)$ and permeable (BFIHOST $\geq 0.65)$.

As there are few gauged small catchments from which to build pooling-groups, users of the FEH statistical method should be aware that similar pooling-groups are likely to be selected for ungauged small catchments, unless they are atypical enough, in terms of other relevant catchment descriptors, that one of these dominates the selection process. Further work will identify if the pooling-group selection method, or the FEH statistical method in general, can be improved for small catchments. Finally, further work is under way within this project to evaluate the performance of $\mathrm{ReFH} 2$ when used in combination with the latest FEH13 rainfall model, as improved rainfall estimation will result in an improved rainfall-runoff model that is more robust in ungauged catchments.

\section{References}

1. Institute of Hydrology (1999). Flood Estimation Handbook (five volumes). Institute of Hydrology, Wallingford.

2. Faulkner, D., Kjeldsen, T., Packman, J. and Stewart, L. (2012). Estimating flood peaks and hydrographs for small catchments: Phase 1. Report SC090031/R, Joint Defra/EA FCERM R\&D Programme. http://evidence.environmentagency.gov.uk/FCERM/Libraries/FCERM_Project Documents/SC090031 Phase 1_Technical_Report.sflb.ashx

3. MacDonald D. E. and Fraser R. J. (2014). An improved method for estimating the median annual flood for small ungauged catchments in the United Kingdom. Journal of Flood Risk Management, 7, 251-264.

4. CEH (2015). FEH Web Service. https://fehweb.ceh.ac.uk

5. National River Flow Archive (2014). http://nrfa.ceh.ac.uk/winfap-feh-files

6. Kjeldsen, T. R., Jones, D. A. and Bayliss, A. C. (2008). Improving the FEH statistical procedures for flood frequency estimation. Science Report SC050050, Joint Defra/EA FCERM R\&D Programme.

7. Wallingford HydroSolutions (2015). The Revitalised Flood Hydrograph Model ReFH2: Technical guidance. November 2015. http://files.hydrosolutions.co.uk/refh2/ReFH2_Techni cal_Report.pdf

8. Kjeldsen, T. R., Stewart, E. J., Packman, J. C., Folwell, S. S. and Bayliss, A. (2005). Revitalisation of the FSR/FEH rainfall-runoff method. R\&D Technical Report FD1913/TR. Defra, London.

9. Dalrymple, T. (1960). Flood-Frequency Analyses. Manual of Hydrology: Part 3. US Geological Survey Water-Supply Paper 1543-A. Washington DC: United States Government Printing Office. 
10. Hosking, J. R. M. and Wallis, J. R. (1997). Regional Frequency Analysis: An Approach Based on LMoments. Cambridge University Press, Cambridge.

11. Robson, A. and Reed, D. (1999). Flood Estimation Handbook Vol. 3: Statistical Procedures for Flood Frequency Estimation. Institute of Hydrology, Wallingford.

12. Bayliss, A. (1999). Flood Estimation Handbook Vol. 5: Catchment Descriptors. Institute of Hydrology, Wallingford.

13. Kjeldsen, T. R., Jones, D. A. and Morris, D. G. (2014). Using multiple donor sites for enhanced flood estimation in ungauged catchments. Water Resources Research, 50(8), 6646-6657.

14. Kjeldsen, T. R. (2009). Modelling the impact of urbanisation on flood runoff volume. Water Management, 162(WM5), 329-336.
15. Kjeldsen, T. R. (2008). Flood Estimation Handbook Supplementary Report No. 1. The revitalised FSR/FEH rainfall-runoff method. Centre for Ecology \& Hydrology, Wallingford. http://www.ceh.ac.uk/sites/default/files/FEH\%20Sup plementary\%20Report\%20hi-res.pdf

16. Faulkner, D. (1999). Flood Estimation Handbook Vol. 2: Rainfall frequency estimation. Institute of Hydrology, Wallingford.

17. Stewart L., Vesuviano G., Morris D. and Prosdocimi I. (2014). The new FEH rainfall depth-durationfrequency model: results, comparisons and implications. $12^{\text {th }}$ British Hydrological Society National Symposium. Birmingham, 2-4 Sept 2014. 